\title{
O LUGAR DA LITERATURA NOS CURSOS DE LICENCIATURA
}

\section{THE ROLE OF LITERATURE IN UNDERGRADUATE COURSES}

\section{Benedito Antunes ${ }^{1}$}

Resumo: O artigo pretende discutir a formação do professor de literatura em cursos de licenciatura, especialmente o de Letras. Embora esses cursos preparem profissionais para atuar em diferentes áreas que pressupõem a competência para ler e escrever como qualidade básica, a maioria desses profissionais destina-se ao magistério, no qual ensinará Língua Portuguesa, disciplina que comporta também a literatura. Essa condição torna indispensável considerar o trabalho com a literatura em sala de aula como inerente ao perfil do futuro professor, o que nem sempre merece a devida atenção dos cursos.

Palavras-chave: ensino de literatura; leitor literário; formação do professor.

Abstract: This paper was carried out to discuss the background development of teachers of literature in undergraduate courses, mainly the foreign languages and literatures courses. Although such courses are meant for preparing teachers to act in different fields which presuppose reading and writing skills as basic qualities, most of those teachers are meant for a teaching role, in which he/she will teach Portuguese language, a discipline which also comprises literature. Such a condition makes indispensable taking into account dealing with literature in classroom as something inherent to the profile of prospective teachers, what not always receives the due attention in such courses.

Keywords: the teaching of literature; literary reader; teachers' background development.

\section{Introdução}

Nunca se colocou em dúvida que um curso de Letras deva proporcionar o estudo aprofundado de literatura. A maioria desses cursos, porém, abandonou o bacharelado, destinado a formar estudiosos que usarão a literatura para a ampliação de seu horizonte cultural ou para o exercício de profissões específicas, como crítico, editor, revisor etc. Com isso, a formação do professor passou a constituir o foco principal desses cursos, que devem preparar o formador de leitores da Educação Básica. Essa condição tem conduzido, não raramente, a uma compreensão estreita da literatura nos cursos de licenciatura, constrangendo-a a um papel secundário e imediatista no rol de disciplinas. $\mathrm{O}$ problema, portanto, configura-se como uma contradição a ser considerada. Se o estudo da literatura no curso superior não deve ser apartado da preparação de professores, também não se deve

\footnotetext{
${ }^{1}$ Professor de Literatura Brasileira da Universidade Estadual Paulista - UNESP, Câmpus de Assis. Bolsista de produtividade em pesquisa do CNPq. E-mail: benedito.antunes@unesp.br.
} 
reduzi-lo ao trabalho com formas vicárias de satisfazer o universo imaginário de crianças e jovens.

Trata-se de um dilema complexo, agravado pelo desprestígio experimentado atualmente pela área de humanidades e, particularmente, pela atividade docente. Dessa forma, facilmente se relega o estudo da literatura a um dos extremos antes mencionados: ou puro estudo literário, de um lado, ou estrita instrumentalização de objetos ficcionais, de outro, tornando a literatura uma forma artística para poucos ou produto de mercado irrelevante do ponto de vista cultural e humano. Em ambos o casos, a literatura distancia-se de seu papel mais amplo na história da humanidade. Diante da constatação de que essa polarização em pontos extremos está-se tornando recorrente nos cursos de Letras, torna-se necessário redefinir o lugar da literatura na formação do professor de Língua Portuguesa.

O primeiro aspecto que se manifesta nessa discussão é a recusa, fundamentada ou não, dos chamados clássicos da literatura, tanto nacionais como universais. Em possível resposta a um saudável questionamento da falta de diálogo com a literatura produzida na contemporaneidade como objeto de estudo na sala de aula, passou-se à injustificável desqualificação dos autores distanciados no tempo, sob a alegação de que são superados, difíceis ou simplesmente desinteressantes. Trata-se, evidentemente, de uma incompreensão do processo histórico que constituiu os chamados clássicos e principalmente de sua relevância para a compreensão em nível profundo da histórica da humanidade. Esses aspectos serão abordados a seguir, considerando-se a atualidade do saber literário e sua pertinência como objeto de estudo em âmbito escolar.

\section{A literatura como resistência}

Existem vozes apocalípticas, inclusive entre professores, que prenunciam o fim da literatura na escola. Talvez como decorrência de um olhar mais concentrado na matéria-prima de sua profissão, muito frequentemente esses professores acusam os jovens de não lerem mais. Sem dúvida, há hábitos no mundo contemporâneo que, se comparados aos de cinquenta anos atrás, quando a televisão ainda engatinhava e a Internet era apenas vislumbrada, parecem dar razão a esses temores. A situação, porém, não é totalmente verdadeira. Talvez até se leia menos, mas o certo é que se lê de modo diferente. E é isso que precisa ser compreendido para se formular corretamente o problema da leitura literária no mundo contemporâneo.

Segundo pesquisa recente, as novas gerações não só andam cada vez mais grudadas nos aparelhos celulares, como esse hábito interfere fundamente na visão de mundo dos usuários. A psicóloga americana Jean M. Twenge (2018) classifica as últimas gerações 
conforme o comportamento e práticas mais comuns: Boomers (nascidos entre 1946 e 1964); Geração X (nascidos entre 1965 e 1979); Millennials (nascidos entre 1980 e 1994); Geração i (nascidos entre 1995 e 2012) (p. 20). Interessa aqui refletir sobre o último grupo, ou seja, a geração da Internet, que teria hoje entre 7 e 24 anos de idade e seria constituído de alunos que cursam da Educação Básica ao Ensino Superior.

Os jovens que pertencem a esse grupo costumam ter pouco contato físico com outras pessoas, sentem-se mais solitários, são menos religiosos e aceitam melhor as diferenças de gênero, etnia e orientação sexual. Dependendo do ponto de vista, esse perfil apresenta qualidades negativas ou positivas, que não interessa discutir aqui. É preciso, no entanto, atentar para um dado que pode indicar mudanças em relação às atividades escolares. Essa geração, segundo a pesquisa, passa mais de duas horas diárias ao celular, ao menos outras duas na Internet e duas horas em jogos e bate-papo. Com seis horas diárias dedicadas às novas mídias, um adolescente passa atualmente o dobro do tempo on-line se comparado com o de 2006 (TWENGE, 2018, p. 69-70). Além disso, gasta cerca de duas horas diante da TV. Observa-se, portanto, que o jovem dedica muito mais tempo ao uso das tecnologias, em especial o iPhone, do que, por exemplo, a atividades que exigem concentração, como as tarefas escolares e a leitura.

Esse dado, no entanto, não é suficiente para se concluir que o jovem lê menos hoje do que lia há cinquenta anos. Como é sabido, nunca se leu muito na história humana. A prática da leitura literária sempre foi um tanto restrita, e isso não mudará muito, assim como a leitura não deixará de existir como prática. E para quem acha que a comunicação visual acabará de vez com o interesse pela leitura e pela palavra, é bom observar a maneira como os hábitos vão mudando ao longo da história. Práticas que pareciam superadas para sempre retornam com fôlego renovado, em correspondência à necessidade de se encontrar formas de superar a saturação criada por comportamentos massivos. Assim, cabe considerar que a palavra, tanto no âmbito da oralidade quanto no da escrita, continua sendo o principal instrumento de comunicação e de elaboração do imaginário.

Observe-se, a esse propósito, a curiosa notícia recentemente divulgada pelo jornal espanhol El País, segundo a qual a indústria pornográfica estaria inaugurando uma nova maneira de oferecer seus produtos: histórias para ouvir, e não para ver. A matéria jornalística começa com uma observação intrigante e, sob certos aspectos, emblemática para a questão aqui abordada. Lembra a repórter que a palavra falada surgiu antes da escrita, para observar em seguida que o homo millennial (que entrou na história na era da internet) estaria 
invertendo sua trajetória: começou teclando mensagens de texto e depois passou a gravar as mensagens, isto é, a usar a voz. Com um toque de humor, ela ilustra o fecho do círculo com uma historinha ouvida de uma colega: "outro dia escutei dois garotos dizendo: seria legal essa coisa de mandar mensagens de voz em tempo real e com resposta simultânea.” Observa, então, a repórter: “eles acabavam de descobrir a conversa telefônica, dois séculos depois de Antonio Meucci inventar o telefone" (El País, 2 fev. 2019).

Embora engraçada, a histórica comporta um fato importante, o de que as práticas mudam em seus aspectos superficiais, mas muitas vezes mantêm a essência. É o que parece sugerir o tema central da matéria: depois de certa saturação de filmes pornográficos, com imagens explícitas repetidas à exaustão, o público teria passado a sentir a necessidade de algo mais criativo, de que pudesse participar mais ativamente, ainda que no plano imaginário. Estaria surgindo, assim, o audiobook pornográfico, numa aparente contradição da principal característica desse tipo de entretenimento. O que levaria algo tão visual como a pornografia a migrar dos filmes para o áudio? Trata-se de um fenômeno que suscita várias hipóteses explicativas. Uma delas, levantada pela editora Diana Gutiérrez, é que a proposta interessa mais ao público feminino, que estaria passando a consumir mais pornografia ultimamente e cuja sexualidade, diferentemente da dos homens, é menos visual e dá mais importância à voz.

Nessa linha, segue uma observação que interessa diretamente a quem valoriza a literatura mais que outras formas de arte e comunicação, principalmente as visuais. A autora da matéria menciona a sexóloga e ginecologista Francisca Molero, diretora do Institut Clinic de Sexologia de Barcelona e do Instituto Ibero-Americano de Sexologia e presidente da Federação Espanhola de Sociedades de Sexologia, para quem "essa modalidade estimula mais a imaginação e a fantasia, ao obrigar o cérebro a formar suas próprias imagens e não consumir as que já vêm prontas.” Além disso, diz Molero, “a voz também tem muito mais nuances e diz muito mais, com suas modulações, do que o mero significado da palavra que emite".

Com efeito, quem cresceu nos anos 1950/1960 ouvindo radionovelas sabe muito bem o que essa constatação tem de verdadeira. Depois de acompanhar no rádio a novela $O$ direito de nascer (SALOMÓN, 1952), ver na TV, que dava os passos iniciais na telenovela, a história filmada de Isabel Cristina e Albertinho Limonta não deixava de ser uma decepção. Bem, a questão central aqui não é o audiobook pornográfico, mas sim o interesse que a voz humana desperta, seja pela sua agilidade e até privacidade de consumo, seja pela própria capacidade de estimular a imaginação ao narrar histórias. Enquanto o filme cristaliza a imagem, deixando pouca liberdade ao espectador para compor os detalhes de personagens e cenas, a literatura 
vive exatamente dessa necessidade de o leitor preencher todas as lacunas e sugestões com sua colaboração imaginativa. É claro que o cinema e a TV, depois de suas experiências miméticas iniciais, passaram a explorar outros aspectos do realismo da imagem. A literatura, porém, sempre dependeu dessa interação com o leitor.

À vista disso, pode-se chegar a uma conclusão singela: os apocalípticos não devem se desesperar; a literatura, como tudo na história do homem, muda, e é bom que seja assim. Em vez de causar aflição ou perplexidade, as mudanças deveriam estimular os professores a aprender cada vez mais com elas. Aquele que ama a literatura e, não menos importante, pratica um pouco de literatura, ainda que de forma amadora, deveria festejar os desafios que as novas condições vão criando para essa forma de arte. Para o ensino de literatura, a nova atitude, uma vez universalizada, seria um ganho enorme para professores, alunos e para a própria literatura. A proposta, então, seria: que se pense mais nos desafios em vez de se encostar no muro das lamentações; que se valorize mais o presente do que o passado; que se crie mais do que repetir fórmulas de outros tempos. Se a literatura expressa a vida é porque a vida está contida na literatura. E isso precisa ser explorado em todos os níveis, principalmente na escola.

Para aprofundar um pouco mais essa questão, é ilustrativa uma reflexão de Renato Janine Ribeiro (2018) sobre a educação no Brasil, apresentada sob o título de "A cidadania cognitiva". Conforme resume ele, "cidadania cognitiva não é só adquirir um rol de conhecimentos - como o adjetivo cognitiva poderia dar a entender. É também cidadania, isto é, uma atuação no mundo" (p. 229). Transpondo o conceito para o contexto da educação literária, pode-se dizer que estudar literatura não se resume a adquirir um rol de conhecimentos sobre obras, autores e estéticas. É também tornar-se um leitor capaz de atuar no mundo como cidadão.

Seria uma versão do conceito de humanização de Antonio Candido (1995), segundo o qual "a literatura desenvolve em nós a quota de humanidade na medida em que nos torna mais compreensivos e abertos para a natureza, a sociedade, o semelhante" (p.249), acrescido de uma dimensão política mais explícita. Afinal, toda boa leitura ocorre contra algo, raramente é edificante no sentido de conformar-se a uma situação. Ou, como diz Daniel Pennac (1993), “cada leitura é um ato de resistência" (p.80). O conceito de resistência para ele é amplo, pois entende que, em última instância, "lemos contra a morte" (p.81), mas o momento que vive a humanidade, particularmente no Brasil, quase força sua atualização e aplicação contra tudo o que nos oprime. Conforme completa Renato Janine no texto citado, “o cidadão se distingue do 
súdito porque este é passivo, enquanto aquele é ativo" (p. 229). Esse entendimento pode contribuir para se encontrar uma razão para ler literatura na escola que vá além da mera aquisição de conhecimentos.

\section{Que literatura ensinar}

Para quem vai exercer a profissão de professor na Educação Básica, a literatura, em particular a brasileira, constituirá, ao lado da língua portuguesa, a base para ministrar as aulas tanto no Ensino Fundamental II como no Ensino Médio. Certamente, as orientações oficiais já trazem os conteúdos programáticos mais ou menos definidos, quando não descritos em apostilas bimestrais que devem ser seguidas pelo docente. Isso se o próprio docente já não prefere adotar um livro didático, desses que as editoras impingem aos professores.

De um modo ou de outro, o trabalho do professor será mais fácil e talvez mais motivador se ele souber o que fazer diante dessas orientações e do eventual material disponível. A primeira condição para isso é ter clareza sobre a disciplina que irá ministrar. Assim, a primeira questão que se apresenta para ele é: "o que eu entendo por literatura?" Talvez esta seja para muitos a questão mais onipresente durante um curso de Letras, respondida ou não, mas que deve assumir um novo caráter na iminência de se entrar numa sala de aula na condição de professor, pois a literatura será vista não mais como algo destinado ao próprio consumo, e sim como um saber que deverá ser transmitido a crianças e jovens em idade escolar.

Por isso, é preciso começar pela pergunta óbvia: o que é a literatura hoje? As possíveis respostas certamente apontarão para uma variedade de conceitos, conforme o gosto e o interesse de cada um, ou mesmo conforme o ângulo de observação determinado por situações concretas de leitura. A título de exemplo, poderiam ser enumeradas algumas hipóteses, segundo as quais a literatura é: 1) um objeto de prazer estético para pensadores e intelectuais; 2) um mero passatempo como outro qualquer, sem utilidade prática; 3) a expressão de sentimentos e ideias de um indivíduo; 4) um documento social ou histórico; 5) uma forma de conhecimento dos homens e da vida; 6) disciplina escolar.

A enumeração dos conceitos é apenas um exercício especulativo com a finalidade de colocar em cena as diversas maneiras com que cada leitor se relaciona com a literatura. De certa forma, todos os conceitos são válidos, e os leitores podem lidar com mais de um em diferentes momentos de sua vida ou mesmo de seu cotidiano. Alguém pode ler (e não importa ainda o que escolhe para ler) para passar tempo e não vê nas obras nada mais que uma fantasia, que pode ou não se relacionar com sua vida objetiva. Outros podem estudar a 
literatura seja porque a escola a coloca no currículo, seja porque se interessam por ela intelectualmente ou mesmo profissionalmente. Outros ainda podem ver na literatura uma forma complexa de expressão da atividade humana. Neste caso, a obra literária poderá ser tomada como forma de conhecimento estético. Enfim, são inúmeras as maneiras de se considerar a literatura e de desenvolver ou não a experiência de leitura literária.

$\mathrm{Na}$ condição de professor de literatura da Educação Básica, porém, é preciso estabelecer que conceito ou conceitos devem ser adotados. Para muitos docentes, talvez a maioria, a resposta é uma só: a literatura é uma matéria escolar que deve prescrever obras para serem lidas ou comentadas conforme as indicações curriculares ou dos livros didáticos. Como se sabe, essa é a forma menos interessante de tratar a literatura na escola e, sem dúvida, a responsável pelo desamor e mesmo ódio pela matéria que se pode observar na maioria dos alunos. Cria-se, assim, um círculo vicioso: o professor, desmotivado, adota um conceito estático de literatura, que não desperta interesse nos alunos, e estes se desinteressam por algo que lhes deveria ser relevante para a formação humana e social. Ora, se a literatura não fosse considerada importante, ela deveria simplesmente ser retirada dos currículos escolares. E, na verdade, é o que pouco a pouco está acontecendo, seguindo a lei da atrofia: o que não é usado adequadamente perde a função e se extingue.

Bem, diante do quadro aqui delineado, há duas possibilidades: deixar a literatura de lado e dedicar-se ao estudo da língua portuguesa ou descobrir modos de lidar com ela que não sejam mais nocivos do que seu uso inadequado. Evidentemente, é na segunda possibilidade que devem se concentrar os formadores do leitor literário. Quem não pensa assim nem deveria cursar Letras, ao menos no sentido próprio do vocábulo cursar: percorrer, seguir o curso de, frequentar uma sequência de aulas para atingir determinados objetivos numa área do conhecimento.

Supondo que haja concordância com essa preocupação, a primeira pergunta que poderia ser feita é a seguinte: que conceito de literatura se deve adotar para ser professor? Todos os conceitos - poderia ser a resposta mais abrangente. Mas essa resposta ela não faz avançar o raciocínio aqui proposto, por não distinguir os problemas e suas possíveis soluções. Um leitor experiente e desprovido de preconceitos pedagógicos poderia responder com uma afirmação também um tanto genérica, mas muito mais produtiva: deve-se adotar o conceito de literatura de cada um. Isto mesmo: o conceito ideal de literatura deve ser o conceito construído pelo próprio docente ao longo de sua formação. E se ele pensa que ainda não tem nenhum, deve construí-lo antes de entrar numa sala de aula. A afirmação é exagerada, porque 
certamente todos têm um conceito de literatura para seu uso pessoal, assim como os alunos da Educação Básica também têm o seu, ainda que apenas implícito. Pode-se não concordar com um ou com outro, mas esse conceito deveria ser sempre o ponto de partida para qualquer atividade, pois é o mais autêntico para os sujeitos envolvidos no processo de ensinoaprendizagem.

Dessa perspectiva, pode-se começar por admitir que as disciplinas de literatura oferecidas durante o curso de Letras deveriam proporcionar aos alunos as condições necessárias para que formassem seu conceito de literatura, positivo ou negativo, complexo ou superficial, empático ou indiferente. É dessa possível formação que se pode partir. Dos conceitos apresentados anteriormente, o único que deveria ser excluído para essas considerações é o último: literatura disciplina escolar. Essa exclusão é a condição para se avançar numa conceituação original que corresponda ao perfil de cada sujeito. Não se trata de negar a importância da disciplina, até porque ela será o ponto de chegada das reflexões aqui propostas. Talvez por isso mesmo não sirva como ponto de partida, uma vez que essa condição a faria carregar todos os preconceitos que viciam suas práticas.

Para facilitar o raciocínio, pode-se recorrer à definição didática de Antonio Candido que, de certa forma, contempla todos aqueles conceitos. Para ele, a literatura é de natureza complexa e comporta três faces: 1) ela é uma construção de objetos autônomos com estrutura e significado; 2) ela é uma forma de expressão, isto é, manifesta emoções e a visão do mundo dos indivíduos e dos grupos; 3) ela é uma forma de conhecimento, inclusive como incorporação difusa e inconsciente (CANDIDO, 1995, p. 244). Nessas três faces, Candido considera a literatura do ponto de vista da produção e da recepção. Enquanto produção, ela se materializa num objeto autônomo, que funciona como expressão de um sujeito e, de tabela, da visão de mundo de um grupo ou sociedade. Do ponto de vista da recepção, ela funciona como forma de conhecimento do homem e da sociedade. Sua preocupação ao evocar a natureza da literatura é chamar a atenção para seu poder humanizador. Conforme sintetiza em outro ensaio, a literatura "exprime o homem e depois atua na própria formação do homem" (2002, p. 80). Para ele, "a literatura desenvolve em nós a quota de humanidade na medida em que nos torna mais compreensivos e abertos para a natureza, a sociedade, o semelhante" (1995, p. 249). Ao fazer suas observações, Candido procura destacar a qualidade literária como condição para o cumprimento de sua função humanizadora, isto é, tudo o que a literatura pode representar para os leitores depende de sua qualidade. Diz ele: "a função da literatura está ligada à complexidade de sua natureza" (p. 244), e ela atua sobre o leitor principalmente por 
causa de sua elaboração formal. Explicando mais ainda: a "maneira pela qual a mensagem é construída [...] é o aspecto, senão mais importante, com certeza crucial, porque é o que decide se uma comunicação é literária ou não" (p. 245).

Como se pode constatar, num ensaio simples, de preocupação didática, Antonio Candido sublinha diversos aspectos que interessam para esta reflexão. A literatura, para ele, é resultado de uma construção coerente, dotada de sentido; expressa valores do indivíduo que a criou e da comunidade em que vive esse indivíduo; pode funcionar como forma de conhecimento, desde que seja bem realizada do ponto de vista formal. Assim, literatura é forma e sentido, e ler literatura é perceber essa forma e atribuir-lhe sentido. É nesse processo que ela, simultaneamente, exprime e forma o homem.

Antonio Candido foi lembrado porque é mais conhecido do público brasileiro, mas essa percepção está presente em vários autores que refletiram sobre a função da literatura. Recordem-se, como exemplo, as ideias de Todorov que circulam no seu livrinho A literatura em perigo (2009). Para ele também a literatura é uma importante forma de conhecimento e de humanização. Por essa razão, ela deveria ser estudada de modo a "nos fazer ter acesso ao sentido dessas obras - pois postulamos que esse sentido, por sua vez, nos conduz a um conhecimento do humano, o qual importa a todos" (p. 89). Seu pressuposto é que o leitor lê obras literárias "dignas de serem estudadas" (p. 32) "para nelas encontrar um sentido que lhe permita compreender melhor o homem e o mundo, para nelas descobrir uma beleza que enriqueça sua existência; ao fazê-lo, ele compreende melhor a si mesmo" (p. 33).

A primeira lição a tirar dessas considerações é que a literatura tem relevância para o ser humano, o que justificaria seu estudo e transmissão a crianças e jovens. Sem esse pressuposto, nada mais fará sentido. Assim, o professor, de alguma forma, deve concordar com ele. Se ele não concordar, deverá eleger outras razões para ensinar literatura. E se não tiver nenhuma razão, sua profissão deveria ser outra, menos professor de literatura. Num depoimento, ouvido ao acaso, uma professora dizia: "nunca impus leituras aos meus alunos; deixava-os livres para ler ou não, pois eu também não gostava de ler”. Atitude honesta, mas ineficaz. O professor é aquele que professa, isto é, declara publicamente, afirma perante todos, enfim declara-se apto a fazer determinada coisa. Logo, omitir-se diante de uma situação de ensino equivale a negar a sua condição de professor e a própria validade do ensino.

Aceito esse pressuposto, é preciso considerar a segunda condição para o ensino de literatura. A prática tão comum de se estudar a literatura por meio da história literária, isto é, 
apresentando autores e obras como exemplos das tendências estéticas, surgidas em determinados momentos históricos, e só remotamente entrando em contato com o texto literário, não é o método mais favorável para explorar a forma e o sentido nos termos propostos pelos autores citados acima. Trata-se, antes, de um discurso sobre a literatura e não da literatura. Dependendo dos objetivos do professor, pode ser apenas um método auxiliar, destinado a contextualizar as obras e acentuar-lhes sua natureza histórica e social, mas não um objetivo central do ensino. Tomado como ponto de partida, pode desvirtuar a própria natureza do estudo literário. Assim, para apresentar a literatura em sua essência, é preciso encontrar formas de conviver com as obras, penetrar-lhes os sentidos mais recônditos.

Um terceiro aspecto presente nas reflexões dos autores é a qualidade das obras, sua organização textual, que é a condição para que a literatura possa cumprir suas funções mais relevantes. Nesse ponto, é útil retomar o que foi dito anteriormente sobre o conceito ideal de literatura do docente: aquele construído pelo próprio docente. Da mesma forma, a boa obra deve ser, em princípio, aquela que o docente considera boa, isto é, ele deve partir de seu próprio repertório, de seu gosto pessoal e, principalmente, de seu próprio conhecimento crítico. É inútil partir de valores que lhe são apresentados como obrigatórios se para ele esses valores pouco significam. E quando se diz "em princípio" é porque se trata de um ponto de partida mesmo. O professor deve sempre estar disponível para adaptações e aprendizagens novas. Essa disponibilidade é até uma forma de ser professor, aquele que transmite a seus alunos um conhecimento e um método em progresso e nunca concluído ou definitivo.

\section{O que ler na escola?}

Diante dessa proposta, pode-se objetar: mas eu gosto só de romance policial; eu só leio com gosto mesmo literatura espírita, de preferência psicografada; eu leio com prazer história de terror; eu não, prefiro histórias de amor; de minha parte, aprecio literatura infantil, cujos livros são curtinhos. E por aí vai... Não há problema. O que se espera de um curso de literatura é que ele proporcione condições de formar e ampliar o repertório literário dos alunos e dotá-los de um método de análise e crítica. Conhecer autores, tendências literárias, teóricas e críticas não significa aderir a todo esse repertório, mas é a condição para se adquirir a capacidade de escolher. E a essa altura entra um aspecto fundamental do currículo de um curso de Letras: a escolha de determinados autores, obras, princípios, métodos. Se é para ensinar na Educação Básica, por que não se trabalha com um corpus mais próximo do público desse nível de ensino? 
Em primeiro lugar, é preciso combater esse preconceito, muito difundido principalmente por docentes de áreas pedagógicas, que transparece em discursos críticos aos cursos de Letras. Há sempre a acusação de que os programas das disciplinas ignoram o conteúdo a ser desenvolvido nas escolas, o que é um equívoco. Se o curso fosse utilizar como corpus e método o possível programa a ser desenvolvido com crianças e jovens, a situação seria insuportável para os alunos da Graduação, como parece ocorrer nos cursos de Pedagogia quando se trabalha com a literatura. Formação docente não significa treinamento, adestramento. Significa dotar o futuro professor de espírito crítico, de forma que possa aprofundar sua capacidade de ler literatura, atribuindo sentido às obras e encontrando um verdadeiro prazer estético nesse processo. Somente essa formação poderá capacitar o futuro professor a praticar leituras no sentido pleno do termo com alunos mais jovens.

Em segundo lugar, não se deve confundir leitura de clássicos com reverência de autores. Os chamados autores canônicos adquiriram essa condição ao longo da história da cultura. Quando se lê num curso um autor clássico, faz-se jus ao próprio conceito de clássico, aquele que é exemplar, próprio para ser estudado na classe, como representante de um universo, de um tempo, de uma forma de representação, enfim. Não se trata simplesmente de sacralizar, prestar reverência, mas sim de dialogar com graus elevados de experiência humana e cultural. Nesse sentido, proporcionar a leitura de clássicos na sala de aula é uma das obrigações da escola. Italo Calvino, no instigante ensaio "Por que ler os clássicos", depois de defender que "os clássicos não devem ser lidos por dever ou por respeito mas só por amor", admite uma exceção para a escola: "a escola deve fazer com que você conheça bem ou mal um certo número de clássicos dentre os quais (ou em relação aos quais) você poderá depois reconhecer os ‘seus' clássicos” (1993, p. 13).

E para quem acha improdutiva a insistência na leitura de bons autores, pode-se dizer: o tempo para leitura é tão reduzido que, para uma boa formação, é preferível conhecer primeiro os picos da experiência literária e só depois, para deleite próprio ou para pesquisa, passar aos vales. Até porque são os picos que criam referência para que os vales sejam desfrutados.

Se essa premissa for aceita, vai surgir um novo questionamento: se o futuro professor é instado a ler apenas obras que lhe interessam e com métodos críticos que não se aplicam aos alunos da Educação Básica, como saber depois utilizar esse aprendizado para ensinar as crianças e os jovens? O próprio Todorov formula essa questão no livro mencionado. Ao tratar do papel do professor do Ensino Médio, toca o cerne da questão: 
O professor do ensino médio fica encarregado de uma das mais árduas tarefas: interiorizar o que aprendeu na universidade, mas, em vez de ensiná-lo, fazer com que esses conceitos e técnicas se transformem numa ferramenta invisível. Isso não seria pedir a esse professor um esforço excessivo, do qual apenas os mestres serão capazes? Não nos espantemos depois se ele não conseguir realizá-lo a contento. (TODOROV, 2009, p.41)

Essa, de fato, parece a questão central dos cursos de Letras. Se não é o caso de instrumentalizar o futuro professor, ensinando-lhe fórmulas para serem replicadas na escola, também não se aceita que a Universidade ignore completamente a profissão que será exercida por ele. Essa ignorância gera um problema que pode ter duas faces: ou o futuro professor não tem a menor ideia do que fazer em sala de aula e se apega aos livros e orientações didáticas, ou acaba repetindo o modelo de aulas que teve na universidade. Nos dois casos, haverá inadequação. Como fazer, então? Aqui entra a importância de se ter clareza na elaboração dos programas e na forma de desenvolvê-los. Um curso de Licenciatura não tem como objetivo central formar crítico literário, pesquisador ou diletante da literatura. Pode até contribuir para isso, mas sua finalidade é formar professores de língua e literatura. E, para isso, deve-se privilegiar a competência linguística, estética e crítica, pois será a partir dessa competência que o futuro professor poderá adquirir a desejada autonomia mencionada anteriormente.

À vista dessas considerações, o conteúdo programático das disciplinas de literatura deve contemplar os objetivos gerais de formação de um professor num curso de Letras, que não se confundem com os da Pedagogia, por exemplo, no tocante ao trabalho com o texto literário. Embora a Literatura Brasileira seja jovem e seu patrimônio, reduzido, o número de bons autores e obras é imenso para ser trabalhado ampla e aprofundadamente. Por isso, é preciso reconhecer que a formação de um verdadeiro professor começa nas suas primeiras leituras, assim que ele se alfabetiza, e continua até o fim de sua vida profissional. Portanto, é ilusório propor o conhecimento de obras fundamentais num curto período de estudo. Esse conhecimento deverá pressupor sempre um antes e um depois. Ainda assim, as disciplinas devem manter a preocupação de colaborar para a constituição de um repertório crítico e literário de seus alunos, uma vez que a formação proporcionada pelo Ensino Médio (para não falar de todo o Ensino Fundamental) tem deixado a desejar.

Assim, esse repertório é pensado principalmente como amostragem, de forma que as disciplinas fazem recortes do patrimônio literário, histórico e crítico. Ainda que esse recorte expresse a formação e o gosto pessoal dos professores que se encarregam de cada disciplina, sua pertinência justifica-se pela orientação geral mencionada acima. Por isso, é comum que os programas deem preferência a autores já clássicos, no sentido indicado anteriormente. 
Especialmente no caso dos escritores, é preciso reiterar que a condição de clássico ou canônico remete não tanto à sua sacralização pela crítica ou mercado editorial, mas sobretudo à sua condição de picos mais elevados da experiência literária. Conforme vem sendo sugerido, com o auxílio dos teóricos e críticos, também eles de certa forma clássicos, cada um desses autores realizou uma experiência original e radical com a linguagem literária. Nos termos de Ezra Pound, trata-se dos inventores, que seriam imitados pelos mestres. Como é sabido, Pound diz, no $A B C$ da Literatura, que a literatura tem sido criada pelas seguintes classes de pessoas:

1. Inventores - "Homens que descobriram um novo processo ou cuja obra nos dá o primeiro exemplo conhecido de um processo";

2. Mestres - "Homens que combinaram um certo número de tais processos e que os usaram tão bem ou melhor que os inventores";

3. Diluidores - "Homens que vieram depois das duas primeiras espécies de escritor e não foram capazes de realizar tão bem o trabalho";

4. Bons escritores sem qualidades salientes - "Homens que tiveram a sorte de nascer numa época em que a literatura de seu país está em boa ordem ou em que algum ramo particular da arte de escrever é 'saudável'. Por exemplo, homens que escreveram sonetos no tempo de Dante, homens que escreveram poemas curtos no tempo de Shakespeare ou algumas décadas a seguir, ou que escreveram romances e contos, na França, depois que Flaubert lhes mostrou como fazê-lo".

5. Beletristas - "Homens que realmente não inventaram nada, mas que se especializaram em uma parte particular da arte de escrever, e que não podem ser considerados 'grandes homens' ou autores que tentaram dar uma representação completa da vida ou da sua época".

\section{Lançadores de modas (1973, p. 42-3).}

Após essa classificação, que tem seu tanto de provocação, mas expressa uma possível hierarquia de escritores quanto à qualidade do que produziram ou produzem, Pound conclui:

Enquanto o leitor não conhecer as duas primeiras categorias, será incapaz de "distinguir as árvores da floresta". Ele pode saber de que "gosta". Ele pode ser um "verdadeiro amador de livros", com uma grande biblioteca de volumes magnificamente impressos, nas mais caras e vistosas encadernações, mas nunca será capaz de ordenar o seu conhecimento ou de apreciar o valor de um livro em relação a outros, e se sentirá ainda mais confuso e menos capaz de formular um juízo sobre um livro cujo autor está "rompendo com as convenções" do que sobre um livro de oitenta ou cem anos atrás. (1973, p. 43) 
Com efeito, é fácil perceber na contemporaneidade brasileira poetas e romancistas que desenvolvem ou retomam o estilo de Oswald de Andrade, de Manuel Bandeira ou de João Cabral de Melo Neto, assim como acontece com o estilo de um Graciliano Ramos, Guimarães Rosa ou Clarice Lispector. Aqui se aplica a imagem dos vales e picos. O ideal seria justamente estudar essa relação, mas isso fica também sugerido, pois caberia mais propriamente num curso monográfico, destinado a uma especialização no assunto. Por isso autores como esses devem ser objeto de estudo num curso de Letras, sem prejuízo da leitura de outros textos para aqueles que desejarem aprofundar seus conhecimentos literários. A articulação dos textos em sala de aula terá a finalidade, de um lado, de aprofundar a leitura de uma obra ou questão estética; de outro, de contextualizar a produção e a recepção dessas obras, procurando ampliar seus sentidos unitários num saber mais amplo, de natureza cultural, que por sua vez poderá contribuir para a compreensão de aspectos históricos e sociais do país e do mundo e, de tabela, permitir que os alunos elejam "seus" clássicos ou se tornem capazes de distinguir as seis categorias de Pound. Trata-se, claro, de construir perspectivas de leitura que não poderão ser plenamente completadas, mas apenas indicadas para que cada um possa se desenvolver e eleger o objeto de estudo a ser aprofundado.

\section{Considerações finais}

Ainda uma palavra sobre o uso da experiência aqui descrita no ensino da literatura na Educação Básica. Não se pode esquecer que um curso de Licenciatura procura formar o professor que vai atuar naquele nível de ensino. Mas esse professor vai formar cidadãos cuja maioria não terá a literatura como objeto de estudo ou de trabalho profissional. Essa é a questão central: antes que as crianças e jovens digam que estudar literatura não serve para nada, e o professor, sem argumentos mais consistentes, apenas faça ameaças com os exames vestibulares e concursos profissionais, é preciso que os alunos sejam levados a descobrir o fascínio que pode ter a experiência de ler uma obra literária e lhe atribuir sentido, o que equivale, guardadas as devidas proporções, à experiência de olhar para vida e the atribuir sentido, "sugerindo um modelo de superação do caos", como diria Antonio Candido (1995, p. 245).

Nesse sentido, ninguém escapará da tarefa de adaptar a experiência adquirida num curso de Graduação à experiência de ler com crianças e jovens. E é possível que a fórmula para essa passagem esteja na convivência intensa e honesta com alguma forma literária. Daí a importância de se criarem repertórios e métodos de leitura, até mesmo pela confrontação desse repertório com outros que possam despertar mais interesse no futuro professor e pela 
criação de métodos que sejam ditados pelo contexto escolar em que o professor irá trabalhar. Se o professor tiver clareza do que poderá representar a literatura para aquele universo e tiver consciência do que de melhor ele poderá oferecer aos seus alunos, será possível fazer viver a literatura no que ela tem de essencial: expressar a vida humana e social e permitir que ela seja compreendida de forma complexa e criativa tanto pela criança e pelo jovem da Educação Básica quanto pelo adulto que enfrentará as belezas e as contradições da vida ao longo de sua existência.

Para isso, é preciso considerar a relação do aluno (e do professor, claro!) com a própria vida pessoal e social. Recorde-se a esse propósito o que disse o filólogo português Fidelino Figueiredo, citado por Lívia Ferreira: "só quem de perto ou de longe tem no espírito algum aspecto do drama do homem, em sua luta com o ambiente e em sua fúria de libertação e interpretação, pode aprender literatura e nela achar o que responde às suas curiosidades e angústias" (1970, p, 3).

A questão que se apresenta aqui e deve ser respondida pelos docentes é: no caso da Educação Básica, a quem compete criar nos alunos essa condição para aprender literatura? Se cabe à escola formar os alunos e se a literatura é vista como formadora humana, mas pressupõe uma formação mais ampla, de natureza cultural, social e política, poderia a literatura suprir essa carência formativa contribuindo para criar no aluno o próprio pressuposto para o seu aprendizado? É provável que sim, pois a formação, embora possa ser baseada em métodos didáticos, não é um processo que ocorre em linha reta nem se baseia na relação de causa e efeito. Muitas vezes ela se dá de forma simultânea e mesmo contraditória, o que permite supor que a literatura possa ser considerada objeto de ensino e, ao mesmo tempo, fator constitutivo da consciência do "drama do homem" pressuposto em cada leitor por Fidelino Figueiredo como condição para se aprender literatura.

Assim, estudar e ensinar literatura adquire importância porque são atividades que partem de necessidades sociais externas à escola, e não o contrário. Seria o mesmo que dizer: a literatura é estudada e ensinada nas escolas porque é valorizada pela sociedade, e não que é valorizada pela sociedade simplesmente porque é objeto de estudo na escola. É provável que a escola (e de tabela os professores) não se dê conta disso e esteja contribuindo para eliminar a literatura dos currículos escolares. Se a literatura continua a ser produzida e consumida, não importa de que forma, é sinal de que ela tem importância para os homens. Se ela não está sendo devidamente valorizada na escola é porque sua compreensão está equivocada ou defasada. Por isso é importante que o professor, enquanto sujeito social, leve para a escola a 
literatura que corresponda à visão que ele próprio logrou construir ao longo de sua formação, como resultado de seu esforço de aprender a vida pela literatura.

\section{Referências}

ABUNDANCIA, Rita. Chega o pornô em áudio: esqueça a imagem, pois o som pode ser muito mais excitante. El País, 6 fev. 2019. Disponível em: https://brasil.elpais.com/brasil/ 2019/02/02/tecnologia/1549135690_778047.html. Acesso em: 25.8.2019.

CALVINO, Italo. Por que ler os clássicos. Tradução Nilson Moulin.. São Paulo: Companhia das Letras, 1993.

CANDIDO, A. A literatura e a formação do homem. Textos de intervenção. São Paulo: Duas Cidades; Editora 34, 2002.

CANDIDO, Antonio. O direito à literatura. In: Vários escritos. 3.ed. São Paulo: Duas Cidades, 1995, p. 235-63.

FERREIRA, Lívia. A convivência com os textos. Assis-SP: Faculdade de Filosofia, Ciências e Letras, 1970.

PENNAC, Daniel. Como um romance. Tradução Leny Werneck. Rio de Janeiro: Rocco, 1995.

POUND, Ezra. Abc da literatura. Tradução Augusto de Campos e José Paulo Paes. São Paulo: Cultrix, 1973.

RIBEIRO, Renato Janine. A pátria educadora em colapso: reflexões de um ex-ministro sobre a derrocada de Dilma Rousseff e o futuro da educação no Brasil. São Paulo: Três Estrelas, 2018.

SALOMÓN, Félix Benjamín Caignet. El derecho de nacer, 1952. Novela para o rádio.

TODOROV, Tzvetan. A literatura em perigo. Trad. Caio Meira. Rio de Janeiro: Difel, 2009.

TWENGE, Jean M. iGen: por que as crianças superconectadas de hoje estão crescendo menos rebeldes, mais tolerantes, menos felizes e completamente despreparadas para a idade adulta. Tradução Thaïs Costa. São Paulo: Editora nVersos, 2018. 